Michael Frommer

Director, Research \& Development

NSW Health Department

discussion paper introducing the NSW Health Department's first Research and Development (R\&D) Strategy has recently been distributed. This article outlines the main contents of the paper.

The aims of the strategy are to:

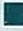

ensure that the State's investment in R\&D over the next 3-7 years generates innovation and is directed toward filling gaps in the knowledge needed to solve present and foreseeable problems in health and health services;

ensure that research-based knowledge is applied in health practice and the development of health policy; and

- build a strong relationship between health R\&D and industry, recognising that the commercial development of research provides opportunities both for economic advancement and the implementation of research-based knowledge.

The strategy deals with the full range of R\&D in the NSW health system, extending beyond programs directly funded by the NSW Health Department. It encompasses biomedical, clinical, epidemiological and operational research, as well as research on the social determinants of health. Its coverage includes priority setting, funding, initiatives to facilitate $R \& D$, the communication of researchbased knowledge, links among research organisations, links between research organisations and industry, monitoring of the outputs and outcomes of R\&D, education and $R \& D$ workforce needs.

To fulfil its aims, the proposed strategy has a short-term and a long-term component.

\section{SHORT-TERM COMPONENT}

The short-term component will be implemented from 199596 and its impact will extend over five years. It begins the process of aligning research with health priorities and provides a consistent policy framework for R\&D. Its main elements comprise an integrated approach to: the establishment of Statewide R\&D policies and the development of R\&D policies in Area and District Health Services;

the funding of research over the period 1996-2000; the training and career development of the $R \& D$ workforce;

the promotion of research so that practitioners and the public know more about research and its importance to health;

the promotion of links among research organisations;

helping research organisations and industry to work together to further the application of research results and realisation of the commercial potential of research; sponsoring a more streamlined process for the ethical approval of research; and monitoring the output and outcomes of research and the extent to which they contribute to the resolution of key health issues.

Implementation of this component of the strategy involves:

$\square$

priority-setting processes

- Statewide and Area- and District-based funding programs;

$\square \quad$ accountability mechanisms;

- provision of support for specific initiatives to facilitate R\&D; and

口 training programs.

\section{LONG-TERM COMPONENT}

The long-term component will also be implemented from 1995-96, but its impact should extend to 2010 . Its premise is that R\&D is an investment in the future. Strategic investment in R\&D over the next 3-7 years will not only yield health gains, but also contribute significantly to economic development. However, because many developmental processes take up to 15 years, a careful assessment of our future needs to 2010 is crucial so our investment in R\&D has a better chance of meeting these needs.

The centrepiece of the long-term component is a foresight process designed to assess the needs of the health system and thus to determine the direction and priorities for $R \& D$ in the first decade of the 21st century. The foresight process will be planned in 1995-96 and undertaken in 1996-97. After wide consultation, the results of the foresight analysis will be incorporated in R\&D planning in 1997-98 and in programs from 1998-99, as the cycle of funding envisaged in the short-term component comes to an end.

\section{RECOMMENDATIONS}

The strategy incorporates 33 recommendations which are given in the text and also listed at the end of the paper. These recommendations:

emphasise the importance of a commitment to both the long-term and the short-term components; propose the establishment of a Research and Development Advisory Committee to advise the NSW Health Department on R\&D policy, opportunities and evaluation; list principles for a Statewide R\&D policy; identify initial research priority areas (cardiovascular disease, cancer, injury, mental health and diabetes), suggest consideration of additional priority areas and propose a commitment of $R \& D$ resources to underpin implementation of Statewide and local plans for improving health outcomes and achieving goals and targets in agreed priority areas; focus Departmental research funding on infrastructure support for major Statewide health and medical research organisations, and establish a competitive basis for the allocation of infrastructure funds; 


\section{NeWS AND COMMENT}

\section{LETTER TO THE EDITOR}

James Harrison, Jerry Moller, John Dolinis

Australian Institute of Health \& Welfare National

Injury Surveillance Unit

\section{Suicide mortality in NSW: geographic variations}

tewart et al raise issues of methodology, the significance

of which extends well beyond the instance of suicide mortality ${ }^{1}$. The recent emergence of an approach to managing public health in Australia (at both State and national levels) through defining, setting and monitoring quantitative targets carries implicit technical challenges, for which most public health practitioners are ill-prepared.

A key challenge is to provide advice that enables policymakers and other users of the information to make good comparisons of values of indicators, over time and between places. Frequently the indicators are derived from complete counts of deaths or hospital separations (and hence have no sampling error) and are expressed as population-based rates. The methods for analysing these data properly are not trivial and are not (in our experience) given much attention in the training that public health practitioners receive in epidemiology and biostatistics.

The article by Stewart et al is at the forefront of attempts to meet this challenge and can also help to describe it. We note that they have calculated confidence intervals on the basis of an assumption that the underlying distribution is a Poisson distribution. An assumption normally required for valid use of this distribution is that the data do not have marked trends. We have not seen time series of suicide for the areas studied and we do not know whether they show marked trends. The point we wish to make applies in any case: questions may arise in the course of routine analysis of these routine data which few public health practitioners have been trained to solve. For example, how much trend would constitute a violation of the Poisson assumption, would such a violation materially affect the findings and what alternative method might be more appropriate?

Selection of an appropriate distributional assumption is a problem that arises in other ways. For example, at the geographic level of analysis used by Stewart et al (Health Areas and Districts in NSW), the Poisson distribution may be the most appropriate in a study of suicide. Is it also the most appropriate in a study at State or national level, where case numbers are larger? On another tack, suicide cases are sometimes found to cluster in time and place. Should the negative binomial distribution be assumed?

Selection of an appropriate distribution is only one aspect of the task. Stewart et al raise the issue of analysing change where case numbers (and sometimes also populations) are small. How might one go about evaluating the impact of a suicide prevention program directed at a population such as that of the Far West Health District?

Most textbooks of biostatistics do not address such questions directly (the best we have seen is the latest in the Statistical Methods in Cancer Research series, only recently published in English $^{2}$ ). As practitioners, we seem to deal with them in one of three ways. We seek advice from a biostatistician (if we have access to one), we "have a go"

\section{Research and development}

Continued from page 91

$\square$ propose that Area and District Health Services develop local R\&D policies and channel funding to support infrastructure for local groups which attract peer-reviewed grant funding;

$\square$ relate $R \& D$ funding to accountability requirements under the NSW Health Department's new program reporting structure;

$\square$ emphasise the importance of effective reporting and communication of research results, to promote the dissemination and application of research-based knowledge and facilitate the monitoring of research outputs and outcomes; seek to foster effective working relationships among different types of research organisations in different localities throughout the State; propose a commitment to R\&D investment in improving - health system planning,

- the organisation of health services, and - clinical, public health and managerial decisionmaking,

with a particular emphasis on health informatics;

including support for institutional ethics committees; support the development of an R\&D workforce, with emphasis on career opportunities in the biomedical sciences and training in health economics, public health and applied epidemiology, clinical epidemiology and health informatics; and propose approaches to monitoring the effectiveness of health and medical research in NSW.

\section{HEALTH INDUSTRY DEVELOPMENT}

Parallel to this strategy, the NSW Health Industry Forum is evolving a plan for health industry development. Issues papers emanating from the Forum expand on points raised in this paper, especially the commercial development of research.

\section{NEXT STEPS}

This discussion paper is being circulated for comment. When comments have been received a workshop will be convened to discuss options and make recommendations on the NSW Health Department's R\&D policy. A final paper will be issued. It will incorporate these recommendations and the Department's response and will set a firm agenda for the implementation of policies and plans.

Copies of the discussion paper can be obtained from Amanda Lees, R\&D Policy Branch, Centre for Research $\&$ Development, NSW Health Department (telephone 02 391-9204). 